\title{
Psychological Analysis and Thinking on the Learning Motivation of China's Adult Higher Education Students-A Survey of Adult Higher Education in Jinan University ${ }^{*}$
}

\author{
Wen Zi-qin \\ Jinan University, Guangzhou, China
}

\begin{abstract}
Adult higher diploma education is an important part of China's higher education. However, in recent years, a considerable part of adult higher education students' learning motivation and attitude is not correct, and this tendency seems to be conspicuous day by day, which is concentrated on the negative learning psychology of "juggling the exam, just for the diploma." It not only weakens the effect of teaching, but also affects the quality and reputation of adult higher education graduates. In this paper, according to the anonymous questionnaire survey results, combined with the basic situation and characteristics of the adult higher education students, the application of psychological principles of learning motivation and attitude deviation of the main causes, and proposed to strengthen the "preach education" that is to guide and inspire the adult students of higher education to learn to establish the correct values, and so its motivation attitude change, of great significance, as well as the contents of "preach education" made a number of ideas.
\end{abstract}

Keywords: adult students, psychological analysis, learning motivation, preach education

\section{Introduction}

Adult higher education students (hereinafter referred to as "adult students") refer to students who receive high school education as a starting point, after "adult higher education entrance examination" admission, to the amateur form (night, weekend, etc.); they complete the required credits and undergraduate degree through certain hours of classroom teaching and course examination.

China's National Middle and Long Term Education Reform and Development Plan (2010-2020) clearly pointed out that "continuing education is an important part of lifelong learning system," and "steady development of adult higher diploma education is needed" (China Network, 2010). With the continuous development of China's higher education, a degree of adult higher education has become an important part of higher education in China. After many years of practice, it showed that adult higher diploma education has trained a large number of practical talents for the society, and the overall development situation is good. However, how to continuously ensure the quality of graduates with record of formal schooling education, to achieve the basic requirement of this specialized subject education to cultivate, or further, achieve social

\footnotetext{
* Acknowledgment: The author acknowledges the financial support from the research project of teaching reform in Higher Education of Guangdong Province (Innovation and exploration of talent cultivation in international undergraduate finance, No.2013060).

Wen Zi-qin, M.A., senior lecturer, Education College, Jinan University.
} 
common recognition, the quality of adult higher degree education still faces a big problem.

To ensure basic quality graduates to teach, teachers must grasp the quality of teaching that affect the quality of graduates of core areas. The real problem of the quality of teaching is the effect of two aspects, "teaching" and "learning" and their interactions. But, in any case, it will eventually be reflected in the quality of learning outcomes and individual students. In short, the intrinsic factors are necessary for the external factors ultimately to take effect. Further, among the internal factors of influencing the learning of individual students, motivation to learn is undoubtedly one of the core elements, which is directly promoting individual students' learning behavior of internal dynamics.

Based on this perspective, this article mainly started with the basic internal cause of "learning" that understanding the psychology of learning motivation and attitude of adult education, and then through investigation and psychological analysis, find out the main problems and causes of its existence, and the external level, from "teaching" according to the several improved thinking and way of thinking.

\section{Adult Students' Learning Motivation Attitude Survey Results and Random Interviews}

The author has engaged in adult education teaching for 18 years. On the whole, adult students' learning motivation and attitudes are good. However, in recent years (especially in the past five years), according to an actual teaching process, the author found that many adult students are not correct in their learning motivation and their learning attitude is not positive, whose most outstanding reflection is "juggling the exam, just for the diploma," and its main performances are that the class attendance rate is low, the classroom discipline is lax, students do not ask questions actively, interactive discussion participation is low, and so on. This issue seems to become increasingly highlight the trend. Some scholars who have studied adult higher education think that the idea of "mixed-mode diploma" is common in adult higher education students (Wang \& Zhang, 2013). In this case, the author and the first-line teaching colleagues conducted a number of exchanges, and we have also reached a fairly consistent agreement. In order to further understand the motivation and learning attitude of adult students receiving higher education, from December 2013 to January 2015, the author invited the adult students who are undergraduate in each grade of the Education College of Jinan University in 12 portions, to fill the questionnaire named "Anonymous Questionnaire on University Class Learning Attitude and Motivation" prepared by the author. A total of 596 questionnaires were issued, 512 valid questionnaires were collected, and the recovery rate was $86 \%$. Following is the questionnaire and statistical results (The statistical results are shown in the brackets next to the options below each question and the item 11 with the highest proportion is in bold).

\section{Anonymous Questionnaire of Adult Students' Learning Attitude and Motivation}

In Table 1, it is noteworthy that in the statistical results of the questionnaire of 11 questions, the highest percentage option "Need more effort" (291, accounting for 56.83\%) of question 6 "Do you think you study hard?" showed the surveyed adult students' overall positive attitude towards learning factor. The remaining 10 questions in the largest number of the highest proportion of 10 options clearly showed that the surveyed adult students' overall learning motivation and attitude were in passive tendencies. Most of the surveyed adult students $(309,60.35 \%)$ chose "To get a university diploma" concerning question 1 "What is the biggest motivation you go to a college?"; the number and proportion are not only significantly higher than that of the sum of the other four options, but also the largest number and the highest proportion of all the options for 11 
questions. It shows that the "diploma motivation" of a considerable part of the adult students of going to college is quite strong. The results are quite similar with the results of a 2011 questionnaire statistical results of Beijing Education Examination "Adult Higher Education Enrollment Examination System Reform Research" task group. The survey shows that in the five options of "accepting adult higher education cause" problem, more than half of the adult students chose "upgrade their qualifications," accounting for $61 \%$ (Yu, 2014).

In addition to the classroom teaching for many years, the author also serves as a head teacher. This makes the author have more opportunities and use other spare time to commonicate with the adult students face-to-face. This is just the author's habit over the years. During a year of continuous anonymous questionnaires, the author focused on the issues about motivation and attitude in the spare time, and has communicated with about 100 persons. The final overall impression is that the learning motivation and psychology of students in the university is just for "university diploma," which is intense and widespread, and their active willingness for learning is not high on the whole. This situation is similar to the author's teaching observation and subjective feeling in recent years, and also approximates the result of the collected 512 anonymous questionnaire survey.

Table 1

Anonymous Questionnaire of Adult Students' Learning Attitude and Motivation

\begin{tabular}{|c|c|c|c|}
\hline & & $N$ & $F$ \\
\hline \multirow{5}{*}{$\begin{array}{l}\text { 1. What is the biggest motivation } \\
\text { you go to college? }\end{array}$} & $\square$ It is an indispensable part of life & 86 & $16.80 \%$ \\
\hline & $\square$ To get a university diploma & 309 & $60.35 \%$ \\
\hline & $\square$ To systematically study the professional knowledge and skills & 79 & $15.43 \%$ \\
\hline & $\square$ Knowledge of their own interest driven & 23 & $4.49 \%$ \\
\hline & $\square$ Urged by friends and undesirable effects & 15 & $2.93 \%$ \\
\hline \multirow{4}{*}{$\begin{array}{l}\text { 2. If not going to school will not } \\
\text { affect performance evaluation, } \\
\text { you will choose: }\end{array}$} & $\square$ As much as possible to adhere to the class & 179 & $34.96 \%$ \\
\hline & $\square$ Nothing to go to class & 207 & $40.43 \%$ \\
\hline & $\square$ Do not go to class & 53 & $10.35 \%$ \\
\hline & $\square$ Look at the majority of students of choice & 73 & $14.26 \%$ \\
\hline \multirow{4}{*}{$\begin{array}{l}\text { 3. What do you think of the } \\
\text { university classroom learning? }\end{array}$} & $\square$ Happy thing & 81 & $15.82 \%$ \\
\hline & $\square$ Boring thing & 54 & $10.55 \%$ \\
\hline & $\square$ Had to do & 214 & $41.80 \%$ \\
\hline & $\square$ Expected things & 163 & $31.84 \%$ \\
\hline \multirow{4}{*}{$\begin{array}{l}\text { 4. How do you think for the } \\
\text { problem of students not going to } \\
\text { class? }\end{array}$} & $\square$ Should not be & 145 & $28.32 \%$ \\
\hline & $\square$ Forgivable & 162 & $31.64 \%$ \\
\hline & $\square$ Does not matter & 121 & $23.63 \%$ \\
\hline & $\square$ Do not know & 84 & $16.41 \%$ \\
\hline \multirow{4}{*}{$\begin{array}{l}\text { 5. What do you think of your own } \\
\text { learning initiative? }\end{array}$} & $\square$ Very high & 46 & $8.98 \%$ \\
\hline & $\square$ High & 118 & $23.04 \%$ \\
\hline & $\square$ General & 301 & $58.78 \%$ \\
\hline & $\square$ Not high & 47 & $9.18 \%$ \\
\hline \multirow{4}{*}{ 6. Do you think you study hard? } & $\square$ Very hard & 35 & $6.83 \%$ \\
\hline & $\square$ Need more effort & 291 & $56.83 \%$ \\
\hline & $\square$ General & 173 & $33.79 \%$ \\
\hline & $\square$ Do not work hard & 13 & $2.54 \%$ \\
\hline
\end{tabular}


(Table 1 to be continued)

\begin{tabular}{|c|c|c|c|}
\hline \multirow{4}{*}{ 7. In class, your focus } & $\square$ Very high & 52 & $10.16 \%$ \\
\hline & $\square$ Higher & 114 & $22.26 \%$ \\
\hline & $\square$ General & 307 & $59.96 \%$ \\
\hline & $\square$ Not high & 39 & $7.62 \%$ \\
\hline \multirow{4}{*}{$\begin{array}{l}\text { 8. Before the commencement of } \\
\text { whether you read the textbooks. }\end{array}$} & $\square$ Have, two times or more & 12 & $2.34 \%$ \\
\hline & $\square$ Yes, only once & 197 & $38.47 \%$ \\
\hline & $\square$ Has had to read & 274 & $53.52 \%$ \\
\hline & $\square$ Do not & 29 & $5.66 \%$ \\
\hline \multirow{4}{*}{$\begin{array}{l}\text { 9. After class, do you review the } \\
\text { learning contents? }\end{array}$} & $\square$ Regular & 45 & $8.79 \%$ \\
\hline & $\square$ Sometimes & 147 & $28.71 \%$ \\
\hline & $\square$ Occasionally & 213 & $41.60 \%$ \\
\hline & $\square$ Do not review & 107 & $20.90 \%$ \\
\hline \multirow{4}{*}{$\begin{array}{l}\text { 10. Do you have communication } \\
\text { with the classroom teacher? }\end{array}$} & $\square$ Regular & 50 & $9.77 \%$ \\
\hline & $\square$ Sometimes & 153 & $29.88 \%$ \\
\hline & $\square$ Occasionally & 207 & $40.43 \%$ \\
\hline & $\square$ No communication & 102 & $19.92 \%$ \\
\hline \multirow{4}{*}{$\begin{array}{l}\text { 11. What do you think of the } \\
\text { learning atmosphere in your } \\
\text { class? }\end{array}$} & $\square$ Very strong & 17 & $3.32 \%$ \\
\hline & $\square$ Strong & 88 & $17.18 \%$ \\
\hline & $\square$ General & 291 & $56.83 \%$ \\
\hline & $\square$ Not strong & 116 & $22.66 \%$ \\
\hline
\end{tabular}

Notes. 1. There is no right or wrong to the answers of the anonymous questionnaires and the results from the questionnaires are just as a reference to research information without any individual presentation and review; and 2. All 11 questions of the questionnaire were single-choice items. Please tick $\sqrt{ }$ according to your true inner thoughts before each option. Thank you very much for your cooperation and assistance.

\section{Psychological Analysis of the Survey Results and the Basic Situation and Characteristics of Adult Students}

Psychology holds that motivation is the behavior of the excitation and guidelines. It is to motivate and sustain human action, and action-oriented to a target, in order to meet certain needs of the individual's internal motivation (David, 2011). It can be seen that motivated people began to produce some kinds of needs. Psychological research shows that, intrinsically, there is a indissoluble link between human needs, motivation, and behavior of the three. In short, human behavior is dominated by the motive, the motive is to be decided. This is a basic law of human psychology and behavior relationships. Kurt Lewin, one of the founders of modern social psychology, summed up the generation of individual behavior formula:

$$
\mathrm{B}=f(\mathrm{P}, \mathrm{E})
$$

It means, human behavior $(\mathrm{B})$ is a function of the individual $(\mathrm{P})$ and the environment $(\mathrm{E})$ interaction. We can simply understand it as: Human behavior is equal to one's own internal situation, external conditions surrounding their interaction functions. In other words, the learning behavior of adult students is by their individual cognitive emotion in learning and form the learning motivation and attitude, such as interaction with their surrounding environment. Therefore, to analyze the causes of adult students' learning motive and attitude deviation, can first born individual adult education $(\mathrm{P})$ is the internal cause, that is, their own basic characteristics, to analyze their needs and motivations of going to university. 
As mentioned above, the adult students need to pass the adult higher education entrance examination, and have finished university with the amateur teaching as the main form. This model of adult higher education through the adult college entrance examination, which began in 1986, has experienced 29 years. At that time, it was subject to the constraints of the ordinary universities scale and the number of students and the normal college entrance examination admission rate is low (in 1986, the normal college entrance examination admission rate was only $30 \%$ ), resulting in the number of higher education graduates far from being able to meet the social demand for talents. Adult higher education entrance examination form of adult higher education model makes up for the deficiencies of the universities in scale defects, but also makes many "normal entrance" lost students, which provides an alternative route to higher education. At the same time, it also gives a large number of the whole society, especially the serving staff, who have not previously had the opportunity to enroll in university a new approach to higher education. Thus, in China, through the entrance into the university, there are two basic ways to coexist: normal college entrance examination and adult higher education entrance examination.

However, with the expansion of the scale of ordinary colleges and universities, the normal college entrance examination admission rate is increasing year by year (up to $75 \%$ in 2012) (Chinese Education Network, 2013). At the same time, the adult higher education entrance examination is also driven by the expansion of enrollment, improve its admission rate, according to statistics 2013-2015 Hebei and other three provinces. The average admission rate of adult college entrance examination is $81.3 \%$ (Test Bar Network, 2015). Two kinds of mode of the college entrance examination enrollment rate of "double high," making that the lower quality of the adult students and the graduates of adult education has always existed, more to the fore. Coupled with recent years, under the influence of some adverse social values, such as "High diploma is equal to high ability," etc., a considerable part of adult students enrolled in universities and other learning attitude motivation and psychological characteristics have also changed.

In this, the author only points out and analyses the characteristics of learning motivation and attitude deviation of the adult students.

\section{Overall Self-Confidence Is Weak}

Most of the adult students, who have passed the adult college entrance examination, have had the normal college entrance examination defeat or related setbacks experience. Compared to the normal college students through the normal college entrance examination (hereinafter referred to as "the normal students"), they have a strong sense of inferiority. If so, deep down, they need to be able to show themselves and enhance their self-confidence. To participate in the adult college entrance examination, acceptance of adult higher education, it can be said that this is to overcome the inferiority complex to enhance self-confidence to reflect the needs of the behavior. This can also be interpreted as a considerable part of the students have a "diploma motivation" of the more prominent psychological reasons.

\section{Career Is Not Satisfactory, Job Promotion Opportunities Are Few}

Due to the rapid development of China's higher education, the proportion of individuals in the whole social groups with university degrees is increasing. Enterprises and other social organizations in the basic standards of recruitment hiring of academic requirements have also been increasing. It has brought considerable challenges and difficulties for the adult students' careers, who have not entered into a college before. Their work is not satisfactory; they have fewer opportunities for promotion and more frequent replacement work. 
From the psychological level analysis, obtained a college degree contribute to cross the threshold of the employment, to improve their self-confidence and self-esteem. For them, the value of a college degree, may be far more than the working group who has obtained a college degree, is much higher. This has been confirmed in the statistical results of the questionnaire of this study, as well as adult students of many interviews exchanges.

\section{The Overall Cultural Knowledge Base Is Low}

Due to the difficulty of adult higher education entrance examination is significantly lower than that of normal college entrance examination, and in recent years, the admission minimum fraction line of adult higher education entrance examination also showed the trend of decline year by year. For example, in 2013-2014 Guangdong Province, the college admission minimum score of adult higher education entrance examination is only 120 points (full marks $=450$ points) (Dade Education Group, 2015). Students' overall cultural knowledge is relatively low. This also leads to the adult students' overall basic knowledge is relatively low and their learning ability is relatively weak, and it is a downward trend year by year. At the same time, this situation may lead to their lack of confidence in the completion of their studies, and may become one of the reasons for the motivation of negative learning. In recent years, the dropout rate of adult students has a significant rise in the situation. According to the author's Academic Affairs Office of Statistics, it showed that nearly five years of the school, adult students' second school year dropout rate increased year by year (the rate wa $3.2 \%$ in 2011 and $4.6 \%$ in 2015 . This also reflects from the side of the adult students of this feature.

\section{Respect for the Need to Be More Prominent}

Psychologist A. H. Maslow proposed the famous five hierarchy of human needs in 1943. He believes that every person has the five needs from low to high, namely, the physiological needs, security needs, social needs, esteem needs, and self-actualization needs, and in each different period, although each person may have several needs, but there is always a need to occupy the dominant position in the main, it conduct for the decisive role. A. H. Maslow's theory is widely recognized and accepted by the academic community.

As previously analyzed, relative to the normal students, the adult students have their special identity; they do not want in the psychological reluctant to be called the adult students by others, coupled with in employment society tend also to them and the normal students to look at the difference between. The pressure from social and psychological, make quite a part of the adult students are the strong inferiority complex (Liu \& Cheng, (2005). They need to be recognized and respected prominent, especially the external respect needs (refers to the individual want others to respect, trust, and high praise). In the questionnaire, the second highest percentage of the first question is "Going to a college is an indispensable part of life" also reflects their strong self-esteem and psychological need to be recognized by society.

\section{The Contradiction Between Work and Study Is More Prominent}

Based on the form of amateur class (night, weekend, etc.) to complete higher education, the vast majority of the adult students are in the job when going to the university; the contradiction between the work and study is more prominent. Night class students often work, hurried to school; weekend class students may also work requires overtime and other factors, school and learning time can not be guaranteed, and they are difficult to devote to learning. This may also lead to their learning initiative is not strong, as well as "learning to cope with" the psychological is more obvious. In recent years, adult education students absenteeism rates also increase. According to the college where the author works, nearly three years to teach, students' average attendance is about $40 \%$. 
In short, when the normal students compared to the adult students in the above-mentioned five characteristics and psychological state, there is a considerable part of the adult students who enter the colleges, with the more obvious motivation and attitude of "payable exam, just for the diploma" of the psychological tendency.

\section{Some Thoughts to Guide and Inspire "Adult Students" to Establish a Positive Learning Motivation and Attitude}

Psychological studies have shown that human cognition, emotion, motivation, and internal factors related to attitudes and behavior point of. $\mathrm{B}=f(\mathrm{P}, \mathrm{E})$ shows that individual motivation, attitudes, and behavior orientation are determined by its internal and external interaction of two factors under formation. In other words, the "adult students," as individual students, their "internal factors" for learning (such as their understanding and motivation for study) and "external factors" for learning (especially the factor of learning environments) are interacted and mutually influenced.

If so, how from the educators "teaching" level, that is, from the external cause of affect students' learning motivation orientation, to guide the incentive adult students the cause of "learning" the main body, make them of the meaning of university have correct cognition, so as to establish a good learning motivation and attitude, especially in the "adult students" on studying at the university of cognition, motivation, and attitude, has appeared deviation. This is a very big problem worthy of attention and deep thinking.

Mentioned how to guide and inspire students from "teaching" level, encouraging them to establish a more positive learning behavior effectively, academic circles generally focus on from the "teach" level, such as the professional courses and the content setting, faculty, teaching method and class and exam discipline strictly implements the improvement and innovation, that is, improve the quality of "teaching." This is obviously right. However, after all, the fundamental measure of "teaching quality" high and low, that is the subject of a learning "adult education" of the quality of the "learning."

Mentioned how to guide and inspire students from "teaching" level, encouraging them to establish a more positive learning behavior effectively, academic circles generally focus on from the "teach" level, such as the professional courses and the content setting, faculty, teaching method and class and exam discipline strictly implements the improvement and innovation, that is, improve the quality of teaching. This is obviously right. However, after all, the fundamental measure of "teaching quality" high and low, that is the learning subject of "adult students" of the quality of the "learning."

Further, under the condition that the "teaching" capability of a teacher is established, the author believes that the students' learning result $(\mathrm{R})$ is approximately equal to the product of learning motivation $(\mathrm{M})$ and learning ability (A), namely, $\mathrm{R}=\mathrm{M} \times \mathrm{A}$. If so, we can think about how to improve the quality of teaching based on the core level "learning," and we can find that the most critical and effective practices or ideas, is to guide and inspire adult students to establish a correct motivation and learning attitude, and try to constantly improve their ability of learning. At the same time, only the internal learning initiative of adult students is inspired, the teaching capacity and effectiveness of a tecaher as an external causes, may receive a "multiplier" effect.

For the teacher's responsibility, 1,000 years ago, the master of education Han at the beginning of his $O n$ Teachers, made a perfect summary: "A teacher is the one who preaches, imparts knowledge, and solves puzzles." This popular saying is articulate: A teacher's role is to spread the truth in life, to teach academic knowledge, and to resolve students' doubts. 
Why did Han Yu put "preaching" in the first place? It is very worthy of our consideration of the teachers. After careful study, it can be found that the order of "preach, imparting knowledge, and solving puzzles" has a strict logical relationship. "Preach," first of all, is to teach students and to teach the correct moral values, that is, we usually say that the moral character, learning motivation, and attitude, such as "ideological education." In other words, first of all, we should take moral education as the basic education. Students are the main body of learning, if they do not have good ideological and moral and correct learning motivation attitude as a basis, it is not possible to do a good job in "imparting knowledge and solving puzzles." Through understanding this sentence of Han $\mathrm{Yu}$, we can also see that Han $\mathrm{Yu}$ is well versed in educational psychology.

To do this, we should first do a good job of preaching for adult students. It is the key, especially in the adult students' initial stage of the newly enrolled, and even in the whole teaching process. This establishes a proactive attitude and motivation for them, which has very important significance.

China's "Teacher Law" clearly pointed out the basic responsibility of teachers is "imparting knowledge and educating people." "Educating people" is not only a matter of primary and secondary education, also in the process of college education (including adult higher education). Teachers should also fulfill the duty of "educating people." The author believes that, especially in recent years, a considerable part of adult students' learning motivation and attitude deviation is conspicuous day by day. So, it is very necessary to pay attention to adult students' preaching education.

How to implement effective preaching education to adult students, the author puts forward some immature ideas:

1. To guide the adult students to establish the correct learning values: Values are the general evaluation and general view of the significance and importance of a person to the objective things around. It has a guiding role in the motivation of behavior, and it also reflects the people's needs and cognitive status. The famous American psychologist V. H. Vroom's motive expectation value theory pointed out that people to take some action motivation or incentive force, depending on the the results of actions of value evaluation and the expected a estimation of the possibility of the results. The simple model: $\mathrm{M}=\mathrm{V} \times \mathrm{E}$ (Motivation = Valence $\times$ Expectancy), namely, motivation determined in action result of psychological evaluation (i.e., "Valence") and the corresponding expected value (Expectancy) of the product. Due to the requirements of the teaching quality of adult higher education, the overall level is lower than the "normal higher education, the adult students to complete the possibility of their studies" (i.e., "Expectancy") is generally higher. Accordingly, to correct the adult students' learning motivation and attitude bias, so that they can form a good learning motivation (M), the key point is to change the value of their learning behavior (i.e., "Valence").

"Preach education," the first thing to guide the adult students, through the correct cognition of university study, set up correct values of learning, to let them understand the diploma is not necessarily represent professional level, deeply realize that only high quality to complete their studies, master professional knowledge and skills, to qualified work persistently and society and the needs of the market. The purpose of establishing correct learning values is to change the learning motivation of the adult students. Let them realize deeply: with true skill and genuine knowledge value, is more important than diploma. Therefore, the author thinks, can refer to the practice of the normal higher education, in the teaching plan of the adult students, it is very necessary to set up the ideological and moral education course that is suitable for them.

2. Self-actualization needs and other characters of the training: The establishment of correct values of learning depends on the cultivation of good character. Compared with the normal students, quite a part of the 
adult students inferiority complex is serious, but in return, their inner sense of urgency and the sense of crisis can also be stronger. So, the adult students' inner potential learning initiative and enthusiasm can highlight some than the normal students. Therefore, through some form of preaching education, their inner sense of responsibility, sense of competition, as well as their potential "self-actualization needs" and other character may be inspired.

"Self-actualization needs" refer to the individual who can play their own potential, to realize personal ideals, aspirations, make oneself become the desired self and community, i.e., the need of a high level of self perfection. In essence, the learning purpose of the adult students in a university is to better adapt to the change of society and life and to improve their ability to adapt and enhance personal competition ability. At the same time, stimulate adult education boost self-actualization needs level, also is helpful to make their inner "external respect needs," more leaning to "internal respect need." "Internal respect need" is a person of an inner self-respect, refers to the individual hope confidence in various environments, can experience their own intrinsic value. "Self-actualization needs" and "internal respect needs" and the establishment of the character, is not only beneficial to the adult students to set up the good study motivation and attitude, but also can enhance their self-confidence, to overcome their inferiority complex.

Therefore, in the whole process of finish their learning, the class teacher and the classroom teacher should often encourage adult students, let them actively participate in teaching activities, and explore their potential ability.

3. Teachers' professional emotional incentive: The formation of students' good learning motivation and attitude depends a lot on teachers' educational and emotional incentive strength. As a passionate, knowledgeable, dedicated love industry of teachers, the nature is easy to attract students won the admiration of students. This attraction and admiration, is bound to be conducive to stimulate students' good learning motivation and interest in learning. Teachers, as the main body of "preaching education," should be done in the first place, the paragon of virtue, lead by example, with its own character to appeal and influence of the adult students, is the so-called "example is better than precept." Therefore, teachers in the classroom teaching process should always keep energetic, convey the vigorous spirit to students, and guide and encourage them to actively participate in interactive teaching, and so on. These characters have a subtle influence on the motivation and attitude to guide and encourage them to establish a good learning motivation and attitude.

Therefore, teachers should actively look for opportunities, such as the use of break and take the initiative to communicate with the students, so as to establish a good teacher-student relationship, a relationship of trust, so it may be "emotionally moving, enlighten them with reason. In words and deeds, teachers should genuinely respect the students "personality and encourage them;" and in the teaching activities, mutual trust and create a good teaching atmosphere and learn from each other; in particular, should avoid to let them there is a feeling of contempt. The teacher in charge should also use their spare time, understand students' learning needs and ideological trends, and to give them "doubts" in, stimulate them to establish correct learning motivation and purpose, training their self-esteem and good academic and aspirant spirit.

To sum up, "preaching education," for "the adult students" set up correct learning value and motivation and attitude, stimulate their initiative of learning behavior, its importance is without doubt, its effect is also imparts knowledge irreplaceable, from the adult students long-term learning and growth effect is even more so. After all, "I want to learn" is far better, more effective, and more durable than "want me to learn." 


\section{Conclusion}

In summary, the author thinks that, after 29 years of development of China's adult higher education, the learning motivation of adult students has generally appeared obvious negative learning psychology that "juggling the exam, just for the diploma." To solve this problem, the key is to put "preach education" in the first place, i.e., starting from the the internal factor of "learning" of the adult students, through educating and guiding to help the adult students" establish correct values in learning, and thus, stimulate them to establish a good learning motivation.

To sum up, there is no doubt that "preaching education" is not only necessary for the adult students to set up a correct learning value, motivation, and attitude, but also is essential for stimulating their learning initiative. And compared with "imparting knowledge," its effect is also irreplaceable, which is more outstanding with regard to the adult students' long-term learning and growth effect. After all, "I want to learn" is far better, more effective, and more durable than "somebody wants me to learn."

\section{References}

China Network. (2010). National medium and long-term plan for education reform and development (2010-2020). Retrieved from http://www.china.com.cn/policy/txt/2010-03/01/content_19492625_4.htm

Chinese Education Network. (2013). The number of high school graduates attending the national college entrance examination and the number of admissions statistics from 1977-2012. Retrieved from http://www.edu.cn/gao_kao_1051/20130507/t2013 0507_939505.shtml

Dade Education Group. (2015). The notice for issuing minimum control fractional line of all kinds of adult college admissions calendar year in Guangdong Province. Retrieved from http://www.dadeedu.com/dg/html/dade_4272.html

David, M. (2011). Psychology (7th ed.) (Huang, X. T., Trans.). Beijing: The Posts and Telecommunications Press.

Liu, F. L., \& Cheng, Y. J. (2005). Adult higher education students psychological characteristics and management. Beijing Financial Sector, 10, 72.

Test Bar Network. (2015). Yunnan 2015 college admission was completed, and the enrollment rate was 80\%. Retrieved from http://gaokao.exam8.com/3358263.html

Wang, Y. M., \& Zhang, J. L. (2013). Views on adult higher education innovation and development. Chinese Adult Education, pp. 11-12.

Yu, Q. D. (2014). Adult higher education problems and improvement strategy research. Journal of Huazhong Normal University (Social Science Edition), 5, 159. 